https://doi.org/10.48009/2_iis_2007_406-411

\title{
DSS FOR DENTAL HOSPITAL EMERGENCY SECTION SIMULATION
}

\author{
Shamsuddin Ahmed, KIMEP, Shamnsuddin_Ahmed@Yahoo.Com \\ Mujibul Haque, KIMEP, mmhaque@kimep.kz
}

\begin{abstract}
This paper presents results obtained from simulating a service system with process oriented simulation methodology. To make the service system responsive and efficient, the SCOR modeling idea is incorporated to build the simulation model. Awesim is a process oriented simulation modeling methodology and so is the Supply Chain Operations Reference (SCOR), developed by supply chain council. A dental hospital case is taken in this study to exhibit how the dental care service system is simulated and design parameters are derived using response surface technique to configure the service efficient and besides responsive. The paper also provides detail sketch of the dental case management practices.
\end{abstract}

Keywords: DSS, Hospital, Service system design, System Time, Awesim, Simulation, Response surface

\section{INTRODUCTION}

Tawam Hospital's Dental Centre is a freestanding dental hospital close to city centre. There are 16 clinics at the Centre exclusively for the general and specialty treatment. There are two clinics at Tawam itself for Oral and Maxillo Facial Surgery, and one fully equipped mobile dental coach.

Tawam Hospital employs 16 general dentists and 14 Consultants/Specialists, representing every clinical specialty. The majority of the dentists and dental specialists have western qualifications and/or experience, and some have held academic appointments at American, Canadian, or European universities. All dental services are provided from emergency dental care to orthogenetic surgery. The Dental Centre is distinguished as one of the first dental facilities in the Gulf region to provide a complete implant dentistry service, specializing in one- and two-stage dental implant placement and reconstruction. The Dental Centre boasts a VIP Clinic with adjoining VIP Lounge for Royal and VIP patients, a conference room with mini-library and projection facilities, and a staff cafeteria. Although the working language at the Dental Centre is English, there are 4 Dental Interpreters who are always available to assist with the Arabic-speaking patients. The divisions of Dental Department are classified as:

1.) Pedodontics Children's Dentistry
2.) Periodontics \& Oral Implantology Diseases of the Tooth Supporting Structures \& Dental Implants

3.) Prosthodontics Fixed and Removable Dental Prosthetics

4.) Oral \& Maxillofacial Surgery Head and Neck Surgery

5.) Endodontics Root Canals

6.) Orthodontics Braces and Dental Orthopaedics

7.) Head \& Neck Pain

8.) Diagnosis \& Oral Radiology.

\section{Simulation as Supply Chain Process Function}

A simple supply chain (SC) can be conceptualized as an integrated network of suppliers, manufacturers and distributors that are linked logically to transform the input or raw material into goods or services to be delivered to a customer according to consumer specification and requirements. Managing such network constitutes supply chain management (SCM) function. The flow in a supply can be characterized by material flow, information flow and cash flow (Herrmann et al. 2003). The process oriented simulation model discussed resembles the concept of the Supply Chain Operations Reference (SCOR) model, Version 4.0(Supply-Chain Council, 2000). The SCOR model describes the business function to deliver goods or services to a customer based on demand and satisfaction. The SCOR model provides a common process oriented language for communicating among supply chain partners in the following decision areas: Plan, Source, Make, and Deliver. These building blocks belong to process categories and can describe a supply chain (Stewart, 1997). Supply-Chain Council (SCC) introduced the SCOR model to assist firms in improving efficiency of the supply chains. Recently, the details for the decision area of Return have been added to the SCOR Version 5.0 model (Lockamy et al., 2004).

In Figure 1, the flow of information and flow of patient in a dental hospital is shown, while Figure 2 translates the process flow as sketched in Figure 1 with the simple Awesim simulation blocks connected logically from one component to another to construct a dental treatment model, where a 
customer request a services. The customer undergoes set of transformation in dental clinic as if an inventory gradually transforms from raw material to semi finished product and eventually a final product to be used by a customer. In this case the customer consumes the services while remain fixed inside the facility and the customer is less mobile. All related facilities moves closer to the customer to provide a customized service. The simulation model interconnects process blocks that describe the functions of the dental hospital patient care services. This is equivalent to SC operation in a network mode.

Configuring SCM from planning view point one can gain competitive advantage (Vickery et al., 1999; Childerhouse and Towill, 2000; Reutterer and Kotzab, 2000; Stock et al., 2000; Korpela et al., 2001a,b; Harland et al., 2001). In this study process oriented Awesim simulation methodology is applied to develop dental hospital service performance.

West et al. (2000) suggests simple and easy to construct simulation model are convenient to implement, change and allow to measure conveniently system performance to augment efficiency and quality.

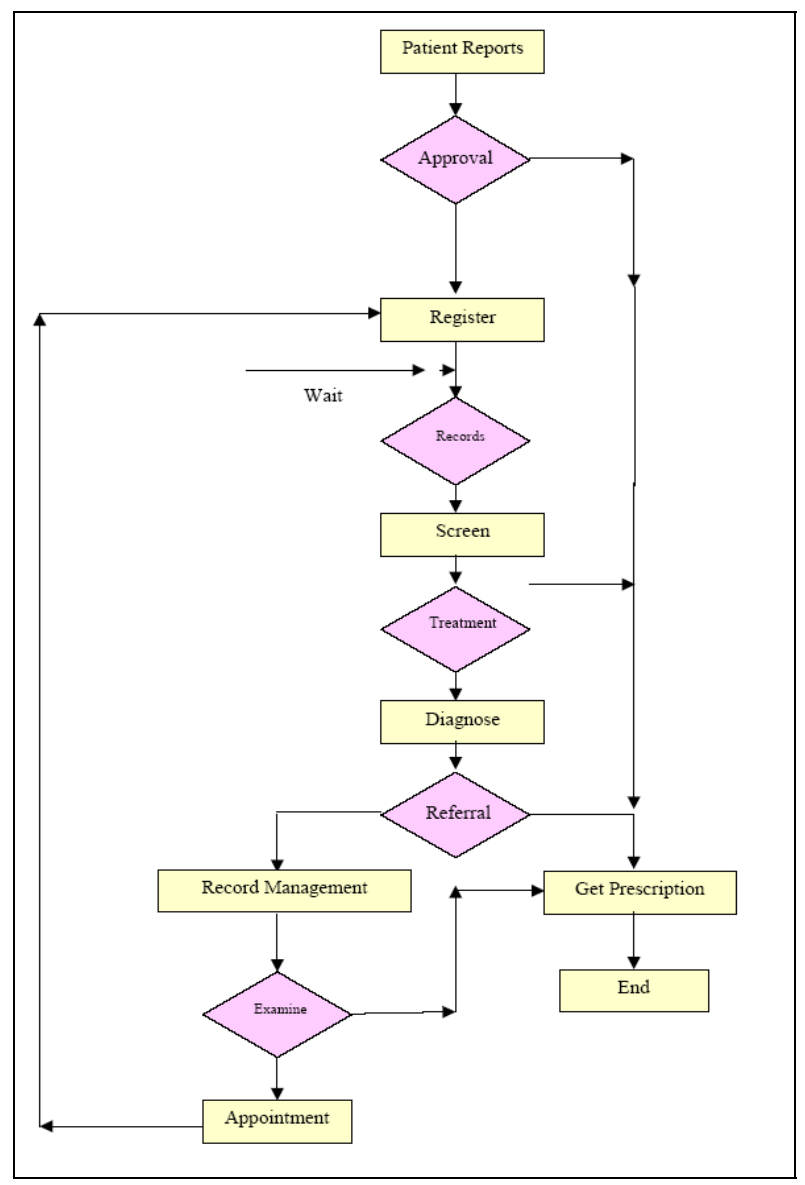

Figure 1: Customer case in a dental hospital

\section{The Clinic Staffing}

The Dental Services department has a total staff of around 120, including 6 Consultants, 8 Specialists, and 16 General Dentists. In addition there are 34 Dental Assistants and 4 Dental Hygienists. The fullservice Dental Laboratory staffs 9 Dental Technicians with a capacity to construct the whole range of Dental Prostheses from simple Acrylic dentures to complex Implant superstructures. In addition, the Dental Centre has a Radiography department, Central Sterilization department, Medical Records department, Pharmacy, Biomedical Technicians, Stores, and Reception and appointments staffs. The staff works on a weekly rotating shift basis, five days per week.

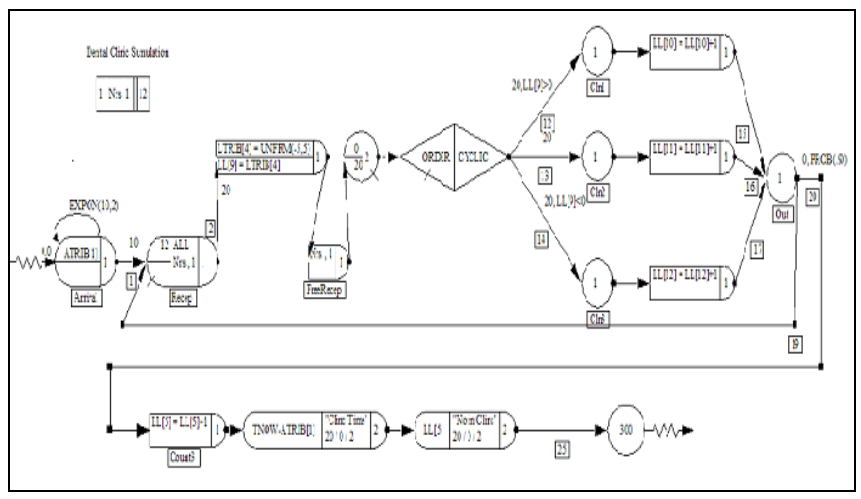

Figure 2: Awesim simulation model customer in a dental hospital

\section{PATIENT ADMISSION MANAGEEMENT}

For dental treatment at the Dental Centre, a patient must be a UAE national or a dependent. To register as a new patient, a copy of a valid UAE passport and photographs must be submitted. A non-national dependent must produce a government certificate verifying the relationship to the UAE national. The Dental Centre Administration has adopted a comprehensive dental care system for its patients. Newly registering patients have screening X-rays taken at the time of registration and given an appointment with a designated Screening doctor. There is one Emergency doctor on each shift who is in control for all emergency patients who report to the Centre. At the Screening appointment, the medical and dental history is reviewed, and the patient is given a thorough oral examination, including charting of existing and required dental work on a priority basis. A comprehensive treatment plan is formulated and presented to the patient. Once the patient has accepted the treatment plan, appointments are made according to this plan. All dental specialties are represented at the Centre except 
Oral \& Maxillofacial Surgery, which is housed at the central Tawam Hospital. The specialists and consultants are immediately available whenever a dentist would require any assistance or consultation.

There are emergency and walk-in patients. The Dental Centre on an average processes 45 emergency patients per day over two shifts. Walk-in patients are accommodated as extras when clinics are available due to cancelled or failed appointments.

The Oral \& Maxillofacial Unit is based at central Tawam Hospital. The clinics specialize in the surgical treatment of patients with cranio/maxillofacial defects, especially orthognathic surgery, temporomandibular joint disorders, cleft lip and palate defects, and facial trauma. Oral surgery sessions are scheduled in every other week at the central hospital. The dental services department facilitates comprehensive general and specialty dental treatment under general anesthesia for pediatric patients who have mental or physical handicaps, who possesses significant medical complications, or who demonstrate obstinate behavior.

\section{Quality management}

As part of the Administration's effort to upgrade the clinical skills and enhance the dental knowledge of its staff, the Dental Services department has established a Continuing Dental Education Program where lectures, seminars, and workshops are scheduled several times a year on current dental topics. The staff is also encouraged to participate by delivering in-service lectures during "Luncheons for Learning". The hospital has seminar series that are associated with medical emergencies and medical complications.

\section{Database maintenance and information processing}

For the purpose of record keeping, patient attendance and clinic statistics are maintained as routine administrative procedures. Each clinic keeps a daily electronic treatment log in order to track procedures completed, patient attendance, emergency and walk-in patients, and failed appointments. The statistics are compiled from database and a monthly summary report is created. The report is dispatched to the hospital central administration for hospital as well as national statistics.

\section{Healthcare strategic plan}

Tawam Hospital in conjunction with the government general hospital collaborates strategically to study projected patient demand up to year 2010. Major capacity expansion is envisaged to accommodate the growing patient population. The new expansion is expected to house the state-of-the-art dental facility with additional 31 dental clinics, including 3 Royal suites. The new faculty would accommodate a multimedia and closed circuit projection lecture hall, library with Internet access computer stations, full cafeteria services, and administrative offices.

\section{Patient Relations Department}

Tawam Hospital, accommodate the most advanced and state of the art equipment, which are, parallel to if not exceed those available in the advanced countries. Among its well-developed support services departments, which are staffed with highly qualified administrative staff, is the patient relations department. It is headed by director of patient relations department, and is assisted by a deputy director of patient relations department and a number of administrative officers. This department plays a major and vital role in the development of health care services being delivered at Tawam hospital. It provides social and counseling services to the patients including translation of various documents, arranging for patients escort to travel with patients requiring treatment abroad, regulating the visiting hours, organizing the treatment process and other services. The Patient Relations Department encompasses the Admissions \& Communications department. Admissions department houses a number of clerks assigned in various areas identified as:

1.) Front desk Female Registration area

2.) Rear desk Male Registration area

3.) Information appointments Specialty

4.) Clinics Mail room Switchboard

\section{Registration}

The Department of Patient Relation functions improve the channel of communication between the staff and patients. The Patient Relations Department is responsible for regulation the treatment process at Tawam Hospital that provides all forms of treatment to all of its customers, and is registered with the medical record. Upon presentation of an accepted identification, the patient is issued with the medical record and a prefix 800 is issued. If the required identification is not immediately available, a patient registers with the authorization of the director of patient relations or an appropriate designee. The patient is informed that he /she must provide proof of identity on their next visit to the hospital. The other patients are registered with the medical record prefix 700. Patient Relations Director or his designee authorizes such patients for availing treatment in this hospital. The employees at the hospital are eligible for all forms of treatment. They are registered with the medical record prefix 50 . The patients who are 
spouses and children of the hospital employees are eligible for treatment. They are registered with medical record prefix 54 . The eligibility are to be proven with documents and approval of the director of patient relations.

Emergency patients and all other patients arriving for emergency treatments are treated without regard to their eligibility status should the patient's condition be considered life threatening by the ER physician. Inpatient treatment will be provided if required. These patients are registered with medical record tag 90. Once the patient is discharged or transferred to another hospital eligibility to readmit is withdrawn. The patient relations director or his designee will review all records of 90 categories patient the following day. The citizens of other countries are not eligible for free treatment unless they fall into the following categories:

1.) Patients referred to Tawam hospital from ministry of health hospitals by means of an official letter classifying the eligibility. The director of patient relations department or his designee, however, reviews the eligibility for treatment every 2 months.

2.) All UAE University students who hold passports from GCC countries may receive treatment at Tawam hospital following authorization from the patient relations director or his designee.

3.) Patients referred to Tawam hospital with a diagnosis of cancer for investigations and treatment is accommodated. Treatment for cancer patient is confined to the disease and its sequel.

4.) All non-national patients are registered with a medical record having prefix 80

5.) The only recognized authority for granting permission for treatment at the hospital are the assistant undersecretary for Al Ain Medical District or Director of Al Ain Medical District or Director of patient Relation or the Deputy Director of patient relations.

All the new patients seeking treatment at the hospital are required to show sufficient identification of a UAE national status. The primary acceptable identifications are:

a.) UAE passport

b.) UAE Citizenship identity card

C.) Birth Certificate and parents passport

d.) Family Census records

The department of patient relations is in command to streamline the processing of medical reports and it's release. When a patient appears at the patient relations department requesting the medical report for the appointed doctor, the administrative officer after consulting the concerned doctor dispatched the records to the concerned doctor along with a form completed by the patient. The hospital has imposed $50 \mathrm{Dh}$. fees as charge to issue medical report if requested by a patient.

The director of the hospital is a link between the hospital administrations and the community it serves. The director of the hospital monitors the health services being delivered at the Tawam hospital to improve the channel of communication between patients and staff. In addition, the functional head also receives patient complaints and regulate the treatment process for non-national patients. The following figure shows the process of admitting patient at the hospital.

The flow chart describes the patient system processing in the dental center with patient visiting in: Pedodontics Children's Dentistry, Periodontics \& Oral Implantology Diseases of the Tooth Supporting Structures and Dental Implants, Prosthodontics Fixed and Removable Dental Prosthetics, Oral and Maxillofacial Surgery, Head and Neck Surgery, Endodontics Root Canals, Orthodontics Braces and Dental Orthopaedics, Head \& Neck Pain and Diagnosis \& Oral Radiology. Also the dental have specialist dentists. The treatment system processing is characterized as:

a.) The patient report at the hospital and an identification number is given for record keeping.

b.) The patient registers in the dental center reception

c.) Patient waits in a room a time to visit the dentist

d.) A medical team does a preliminary diagnose on the patient and decides the treatment needs. The team decides if the patient needs further appointment or not

e.) If the patient doesn't require appointment, then the patient receives a medical prescription finishes the dental center visit

f.) If the patient is recommended an appointment, the receptionist at the appointment centre fixes a time slot to visit a dentist

g.) At the end of consultation, the patient is either gets a further appointment for follow up or the patient is declared fit. The patient in either case 
reports to the appointment desk. The appointed patient continues treatment either same time or in future, while the fit patient is fee to leave the clinic with necessary records and prescriptions

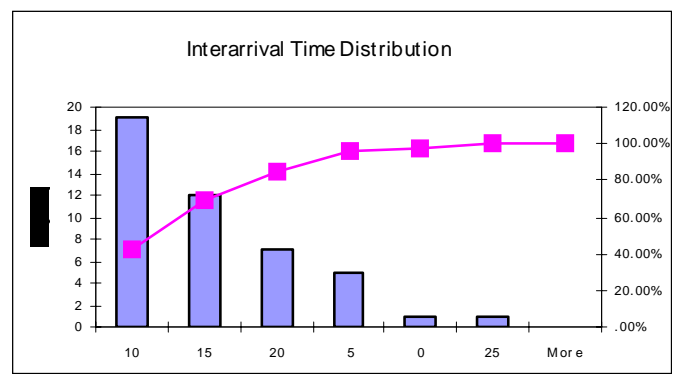

Figure 3: Reception area inter-arrival time distribution

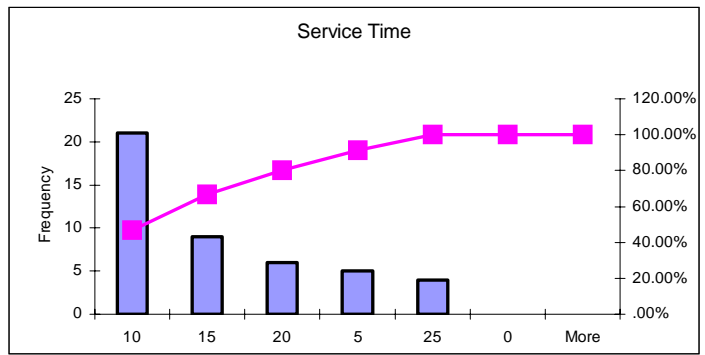

Figure 4: Dental care service time distribution

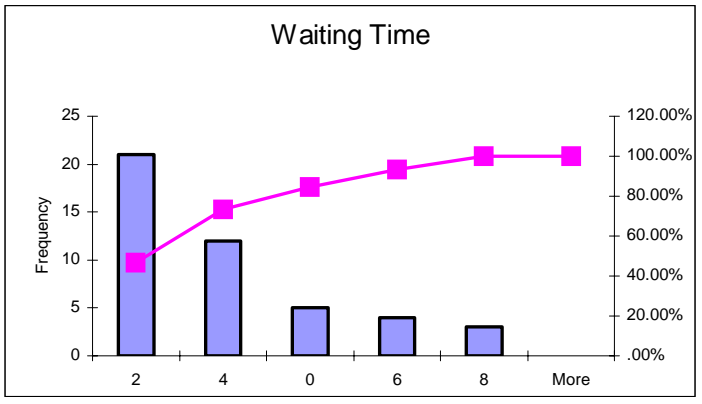

Figure 5: Patient waiting time distribution

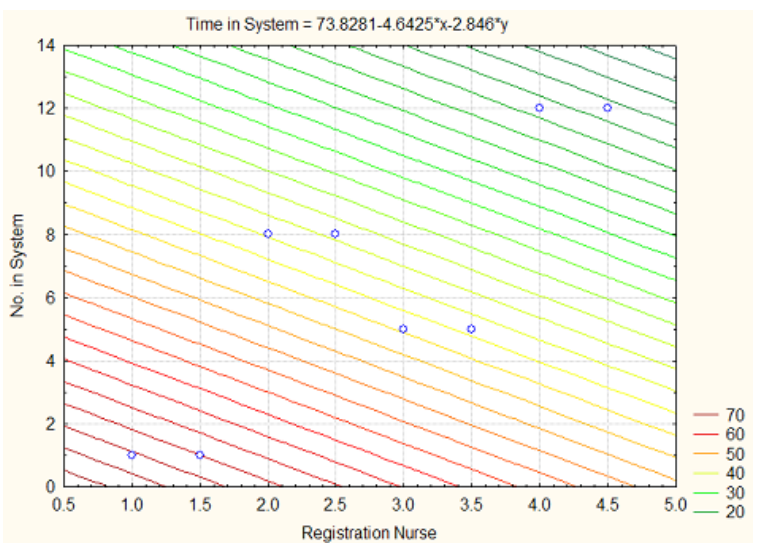

Figure 6: Response surface for Decision Support
Figures 3, 4 and 6 show the time distribution for arrival time of patient in hospital. In simulation the arrival is reconstituted from the inter-arrival time distribution as shown in Figure 3. the service and waiting distribution is shown in Figure 4 and Figure 5 respectively. The simulation model uses the observed time distribution to replicate the actual environment with the iconic model as developed in Figure 2.

\section{RESULTS}

The simulation model is simulated for 100 days. The average time a patient remains in hospital is found to be 70 minutes. This implies from the response surface that if one to two nurses are deployed, the patient processing rate is approximately 2 to 3 corresponding to system time 70 minutes. The figure clearly suggests how to deploy the resources to maximize the patient processing rate. For example, if it is necessary to process more patient, say 8, due to unexpected future demand, without expanding the capacity of the hospital with physical infrastructure, would require at least 5 nurses and the time in system is expected to be about 50 minutes. Observe the system time as 50 minutes approximately that comply with the $\mathrm{x}$ and $\mathrm{y}$ coordinate resources as nurse and number in systems respectively. Similarly, the number of doctors, paramedics and other resources can be matched to make the service systems responsive in SCM context.

\section{CONCLUSION}

It is shown in this study how Awesim, a simulation modeling technique, can capture the process modeling concept as of SCOR. Dental care service system in a hospital is simulated with Awesim model to identify the decision parameters to improve the service system. The SCOR is based on process modeling philosophy, while Awesim also steams from process modeling viewpoint and it hence conveniently assemble SCOR service system model. Further, it is demonstrated that the simulation results conveniently augment the decision support system with response surface methodology. The response surface maps and calibrates the expensive recourses conveniently in a service system to improve the performance of a SC that is either responsive or efficient. A service system SC is responsive if it reduces the systems time, while it is efficient it economizes in resource utilization. Awesim generates detail level of recourse utilization report. However it is not discussed in detail using simulation results due to space limitations. 


\section{REFERENCES}

1. West, A.A., Rahimifard, S., Harrison, R. and Williams, D.J. (2000), "The development of a visual interactive simulation of packaging flow lines”, International Journal on Production Research, Vol. 38 No. 1, pp. 4717-41.

2. Stewart, G. (1997), "Supply-chain operations reference model (SCOR): the first cross-industry framework for integrated supply-chain management”, Logistics Information Management, Vol. 10 No. 2, pp. 62-70.

3. Supply-Chain Council, 2000, Supply-Chain Operations Reference-model, Version 4.0, Pittsburgh, Pennsylvania.

4. Herrmann, Jeffrey W., Lin, Edward., Pundoor, Guruprasad. (2003). SUPPLY CHAIN SIMULATION MODELING USING THE SUPPLY CHAIN OPERATIONS REFERENCE MODEL, Proceedings of DETC'03, ASME 2003 Design Engineering Technical Conferences and Computers and Information in Engineering ConferenceChicago, Illinois USA, September 2-6, pp. 1-9.

5. Lockamy III, Archie., McCormack, Kevin. (2004). Linking SCOR planning practices to supply chain performance: An exploratory study, International Journal of Operations \& Production Management, Vol. 24 No. 12, pp. 1192-1218.
6. Vickery, S., Calantone, R. and Droge, C. (1999), "Supply chain flexibility: an empirical study", Journal of Supply Chain Management, Vol. 35 No. 3, pp. 16-24.

7. Childerhouse, P. and Towill, D. (2000), "Engineering supply chains to match customer requirements", Logistics Information Management, Vol. 13 No. 6, pp. 337-45.

8. Reutterer, T. and Kotzab, H.W. (2000), "The use of conjoint-analysis for measuring preferences in supply chain design”, Industrial Marketing Management, Vol. 29 No. 1, pp. 27-35.

9. Stock, G., Greis, N.P. and Kasarda, J.D. (2000), "Enterprise logistics and supply chain structure: the role of fit", Journal of Operations Management, Vol. 18 No. 5, pp. 531-47.

10. Korpela, J., Lehmusvaara, A. and Tuominen, M. (2001a), "Customer service based design of the supply chain”, International Journal of Production Economics, Vol. 69 No. 2, pp. 193204.

11. Korpela, J., Lehmusvaara, A. and Tuominen, M. (2001b), "An analytic approach to supply chain development”, International Journal of Production Economics, Vol. 71 Nos 1-3, pp. 145-55.

12. Harland, C.M., Lamming, R.C., Zheng, J. and Johnsen, T.E. (2001), “A taxonomy of supply networks”, Journal of Supply Chain Management, Vol. 37 No. 4, pp. 20-7. 